\title{
Refractory Burkitt Leukemia
}

National Cancer Institute

\section{Source}

National Cancer Institute. Refractory Burkitt Leukemia. NCI Thesaurus. Code C151977.

Burkitt leukemia resistant to treatment. 